\title{
Methyltransferase G9A regulates $T$ cell differentiation during murine intestinal inflammation
}

\author{
Frann Antignano, ${ }^{1}$ Kyle Burrows, ${ }^{1}$ Michael R. Hughes, ${ }^{1}$ Jonathan M. Han, ${ }^{2}$ \\ Ken J. Kron, ${ }^{3}$ Nadia M. Penrod, ${ }^{3}$ Menno J. Oudhoff, ${ }^{1}$ Steven Kai Hao Wang, ${ }^{1}$ \\ Paul H. Min, ${ }^{1}$ Matthew J. Gold, ${ }^{1}$ Alistair L. Chenery, ${ }^{1}$ Mitchell J.S. Braam, ${ }^{1}$ \\ Thomas C. Fung, ${ }^{1}$ Fabio M.V. Rossi, 1,4 Kelly M. McNagny, ${ }^{1,4}$ \\ Cheryl H. Arrowsmith, ${ }^{3,5}$ Mathieu Lupien, ${ }^{3}$ Megan K. Levings, ${ }^{2}$ and Colby Zaph ${ }^{1,6}$ \\ ${ }^{1}$ The Biomedical Research Centre and 2Department of Surgery, Child and Family Research Institute, University of British Columbia, \\ Vancouver, British Columbia, Canada. ${ }^{3}$ Princess Margaret Cancer Centre/University Health Network \\ and Department of Medical Biophysics, University of Toronto, Toronto, Ontario, Canada. \\ ${ }^{4}$ Department of Medical Genetics, University of British Columbia, Vancouver, British Columbia, Canada. \\ ${ }^{5}$ Structural Genomics Consortium, University of Toronto, Toronto, Ontario, Canada. \\ ${ }^{6}$ Department of Pathology and Laboratory Medicine, University of British Columbia, Vancouver, British Columbia, Canada.
}

\begin{abstract}
Inflammatory bowel disease (IBD) pathogenesis is associated with dysregulated CD4+ ${ }^{+}$Th cell responses, with intestinal homeostasis depending on the balance between IL-17-producing Th17 and Foxp ${ }^{+}$Tregs. Differentiation of naive T cells into Th17 and Treg subsets is associated with specific gene expression profiles; however, the contribution of epigenetic mechanisms to controlling Th17 and Treg differentiation remains unclear. Using a murine $T$ cell transfer model of colitis, we found that $T$ cell-intrinsic expression of the histone lysine methyltransferase G9A was required for development of pathogenic $T$ cells and intestinal inflammation. G9Amediated dimethylation of histone $\mathrm{H} 3$ lysine 9 (H3K9me2) restricted $\mathrm{Th} 17$ and Treg differentiation in vitro and in vivo. $\mathrm{H} 3 \mathrm{~K} 9 \mathrm{me} 2$ was found at high levels in naive Th cells and was lost following Th cell activation. Loss of G9A in naive $T$ cells was associated with increased chromatin accessibility and heightened sensitivity to TGF- $\beta 1$. Pharmacological inhibition of G9A methyltransferase activity in WT T cells promoted Th17 and Treg differentiation. Our data indicate that G9A-dependent $\mathrm{H} 3 \mathrm{~K} 9 \mathrm{me} 2$ is a homeostatic epigenetic checkpoint that regulates Th17 and Treg responses by limiting chromatin accessibility and TGF- $\beta 1$ responsiveness, suggesting G9A as a therapeutic target for treating intestinal inflammation.
\end{abstract}

\section{Introduction}

The inflammatory bowel diseases (IBDs) are a group of chronic intestinal inflammatory diseases that include ulcerative colitis (UC) and Crohn disease (CD). IBD is thought to occur as a result of a complex interplay between host genetics and environmental factors leading to a dysregulated intestinal immune response (1). A recent meta-analysis of existing genome-wide association studies identified over 160 loci associated with both UC and CD (2). Gene ontology (GO) analysis of these IBD loci showed that the terms "regulation of cytokine production" and "T cell activation" were significantly enriched (2), suggesting that dysregulated production of cytokines by activated $\mathrm{T}$ cells is a critical factor in the development of IBD. Thus, a better understanding of the molecular mechanisms that regulate $T$ cell activation and function may provide novel pathways to target therapeutically.

A pathogenic role for $\mathrm{CD}^{+}$Th cells in intestinal inflammation has been clearly shown in a murine $\mathrm{T}$ cell transfer model of IBD. Adoptive transfer of highly purified naive $\mathrm{CD} 4{ }^{+} \mathrm{CD} 25^{-} \mathrm{CD} 45 \mathrm{RB}^{\mathrm{hi}}$ Th cells into immunodeficient $\operatorname{Rag} 1^{-/-}$mice results in the development of chronic intestinal inflammation, leading to weight loss and death $(3,4)$. Disease pathology of Th cell transfer colitis shares many similarities with human IBD, including transmural inflammation,

Conflict of interest: The authors have declared that no conflict of interest exists. Citation for this article: J Clin Invest. 2014;124(5):1945-1955. doi:10.1172/JCI69592. epithelial cell hyperplasia, loss of goblet cells, leukocyte infiltration, crypt abscesses, and epithelial erosion $(3,5)$. Cotransfer of naive Th cells with purified Tregs abrogates the development of disease (6-9), thus providing a powerful in vivo model to directly test the cellautonomous inflammatory and regulatory capabilities of Th cells.

Th cells differentiate into one of several effector lineages, including Th1, Th2, Th17, and Tregs, which vary in their function (10). Th17 and Tregs are unique among the Th cell subsets in that they are found in high numbers in intestinal tissues in the steady state and their differentiation is controlled by the cytokine TGF- $\beta 1$ (11). Activation of naive Th cells in the presence of TGF- $\beta 1$ and IL- 6 leads to the development of Th17 cells that express the transcription factor retinoic acidrelated orphan receptor- $\gamma \mathrm{t}(\mathrm{ROR} \gamma \mathrm{t})$ and secrete IL-17A and IL-17F (12-15). In contrast, activation of naive Th cells in the presence of TGF- $\beta 1$ and IL- 2 leads to the development of Tregs that express Foxp3 (16). Th17 and Treg differentiation is a reciprocal relationship, as Foxp3 antagonizes ROR $\gamma$ t function $(17,18)$ while ROR $\gamma t$ can repress Foxp3 gene expression (19), and this balance between Th17 and Tregs is critical for intestinal homeostasis. Thus, understanding the molecular mechanisms that control Th17 and Treg differentiation will be important for identifying how dysregulated Th cell responses contribute to the development of intestinal inflammation.

Th cell lineage differentiation is controlled by the activation of lineage-specific gene expression with the concomitant repression of lineage-promiscuous genes through transcriptional and epi- 

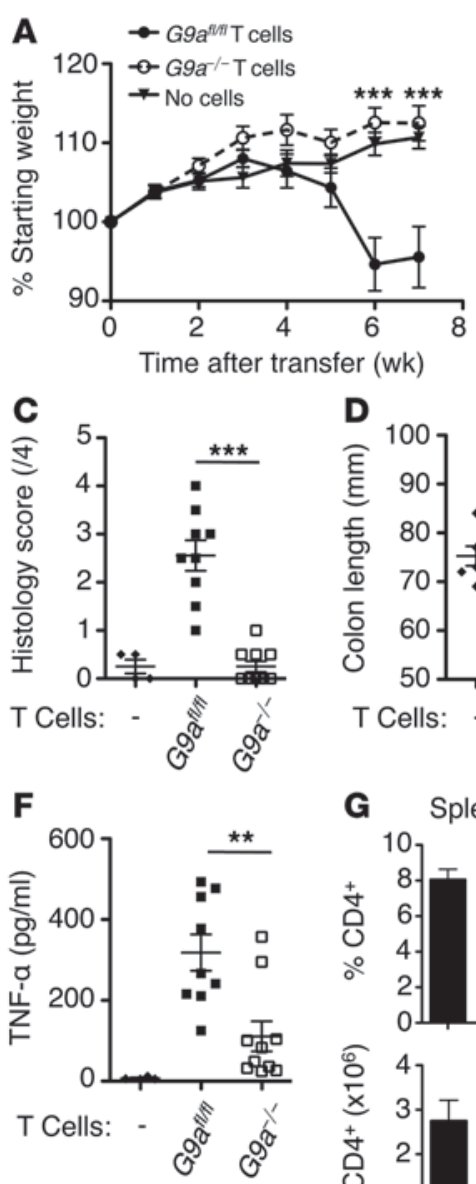

B

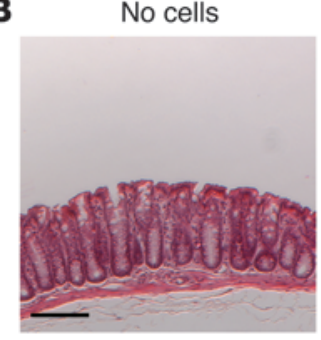

G9a $a^{\text {tint }} \mathrm{T}$ cells

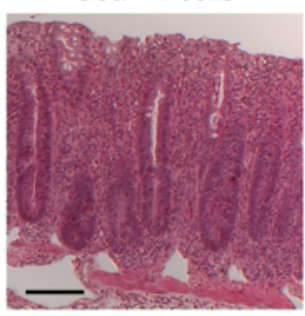

$\mathrm{G9a}^{-/-} \mathrm{T}$ cells

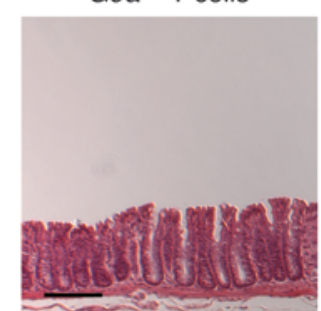

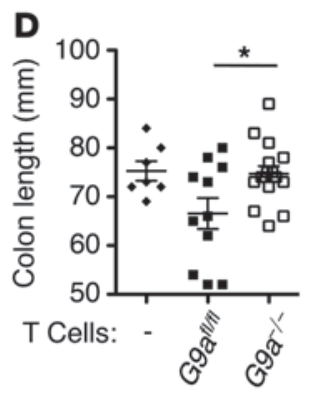
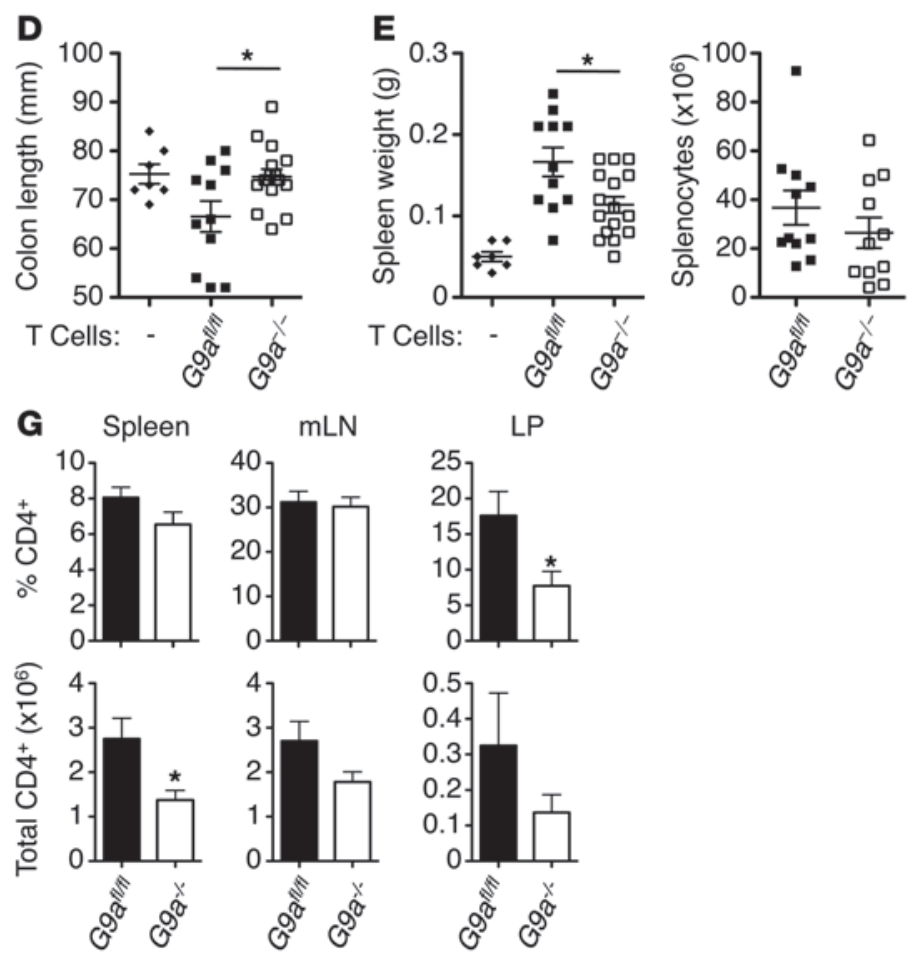

Figure 1

G9A is required for the development of experimental colitis. CD4+CD25-CD45RB hi naive T cells $\left(4 \times 10^{5}\right)$ from G9a ${ }^{f / f l}$ or G9a ${ }^{-/-}$mice were transferred into Rag $1^{-/-}$mice and monitored for colitis. (A) Weight loss (percentage of initial weight) was calculated for each mouse over 7 weeks. (B) Representative sections of H\&E-stained proximal colons. Scale bars: $100 \mu \mathrm{m}$. (C) Colitis was assessed histologically at 7 weeks after transfer, and severity of inflammation was scored. (D) Colon length, (E) spleen weight and cellularity, and (F) serum TNF- $\alpha$ were analyzed at 7 weeks after transfer. (G) Frequency and total number of CD4+ $\mathrm{T}$ cells in spleen and $\mathrm{mLN}$. Each point represents an individual mouse, and the data are from 2 of 4 independent experiments ( $n=5-8$ per experiment). Statistics compare Rag $1^{-1-}$ mice that received G9a $a^{f / f f} T$ cells to those that received G9a ${ }^{-1-}$ T cells. ${ }^{*} P<0.05 ;{ }^{* \star} P<0.01 ;{ }^{* \star} P<0.001$. Error bars indicate SEM.

genetic mechanisms (20). A general epigenetic model of cellular lineage differentiation has emerged, in which activating epigenetic modifications are found at lineage-specific genes while repressive epigenetic modifications accumulate at lineage-promiscuous loci (21). For example, acquisition of activating histone modifications, such as acetylation of lysines 9 and 14 in histone $\mathrm{H} 3$ (H3K9/14Ac) or trimethylation of lysine 4 in histone $\mathrm{H} 3$ ( $\mathrm{H} 3 \mathrm{~K} 4 \mathrm{me} 3)$, is associated with gene expression, while repressive epigenetic marks, including $\mathrm{H} 3 \mathrm{~K} 9 \mathrm{me} 2, \mathrm{H} 3 \mathrm{~K} 9 \mathrm{me} 3$, and $\mathrm{H} 3 \mathrm{~K} 27 \mathrm{me} 3$, are found at lineage-promiscuous and silenced genes (22). In Th cells, H3K9/14Ac modifications are enriched at the promoters of lineage-specific genes such as Rorc in Th17 cells and Foxp3 in Tregs $(23,24)$. It has also been shown that H3K27me3, mediated by the polycomb repressive complex (PRC) member Ezh2, is acquired at silenced loci during Th cell differentiation (24), while Suv39h1/2-depen- dent $\mathrm{H} 3 \mathrm{~K} 9 \mathrm{me} 3$ is acquired at lineage-promiscuous loci in Th2 cells and is required for Th2 stability (25). However, a full understanding of the functional role of epigenetic modifications in the regulation of $\mathrm{Th}$ cell differentiation remains unclear.

The role of the repressive histone modification $\mathrm{H} 3 \mathrm{~K} 9 \mathrm{me} 2$ during Th cell differentiation is not fully understood. H3K9me2 is mediated by the methyltransferase G9A (Ehmt2, Kmt1c) (26-28), which has been shown to regulate cellular differentiation of embryonic stem cells (29), silence facultative heterochromatin during X chromosome inactivation (30), inhibit pluripotency-associated genes in induced pluripotent stem (iPS) cells $(31,32)$ and, mediate innate type 1 IFN response after viral infection (33). These studies suggest that G9A mediates epigenetic silencing of nonspecific loci during lineage differentiation. However, we have previously shown that G9A is dispensable for repression of lineage-promiscuous genes 
A

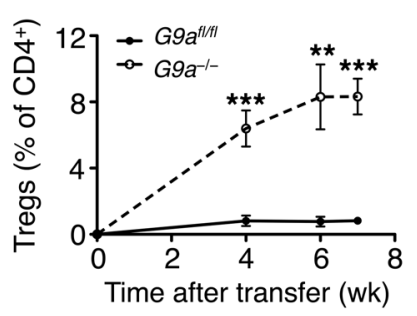

C Spleen
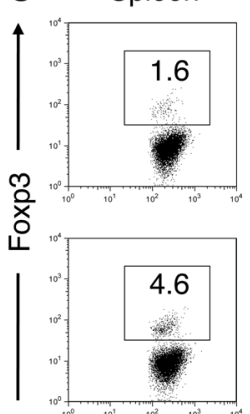

$\longrightarrow$ CD4

E

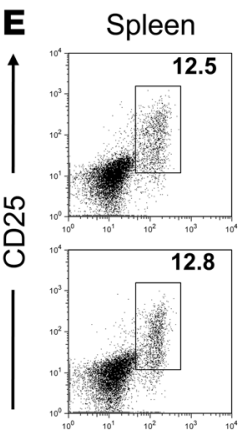

mLN
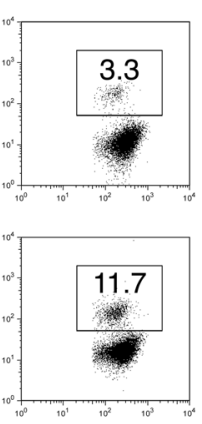

$\mathrm{mLN}$

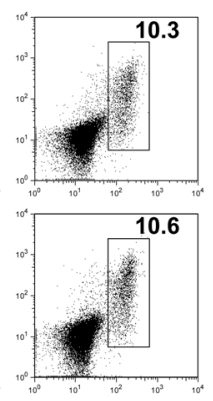

Foxp3
B

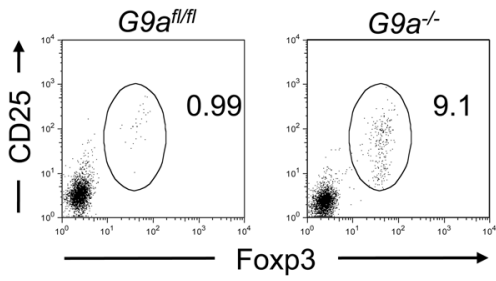

LP
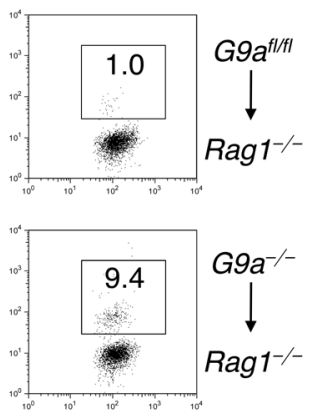

$\operatorname{Rag} 1^{-1-}$

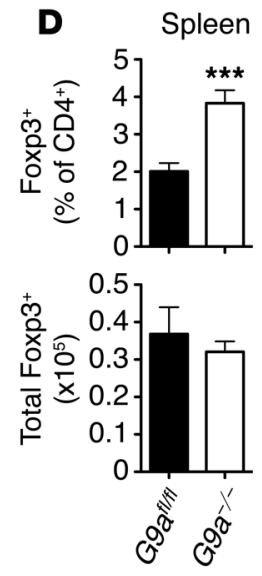

F
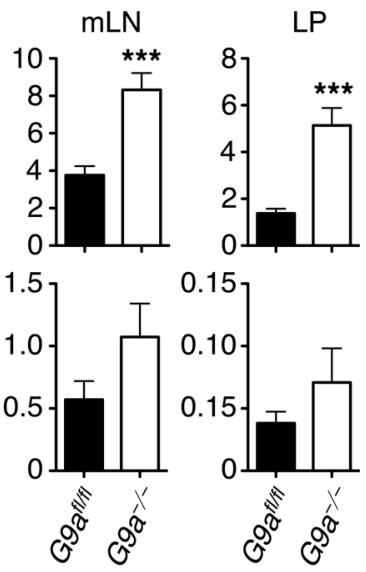

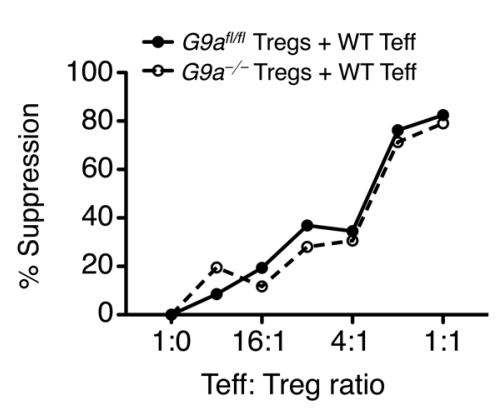

Figure 2

Expansion of Foxp3 ${ }^{+}$Tregs after transfer of naive G9a ${ }^{-/-}$Th cells into Rag $1^{-/-}$mice. CD4 ${ }^{+}$CD25-CD45RB ${ }^{\text {hi }}$ naive T cells $\left(4 \times 10^{5}\right)$ from G9a ${ }^{\text {flffl }}$ or

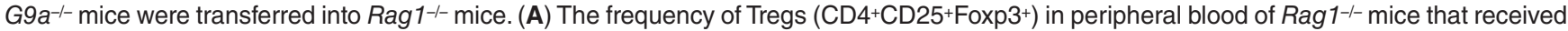
$\mathrm{G9a}^{\text {fllfl }}$ or $\mathrm{G9a}^{-1-}$ T cells was quantified by flow cytometry. (B) Representative CD25 and Foxp3 staining of peripheral blood CD4 ${ }^{+}$cells at 7 weeks after transfer. Numbers represent frequency of CD4+CD25+Foxp3 ${ }^{+}$cells. (C) Representative CD4 and Foxp3 staining and (D) quantitative analysis of the frequency and total number of Foxp3 $3^{+}$cells from the spleen, $\mathrm{mLN}$, and LP from Rag $1^{-/-}$mice receiving G9a $\mathrm{allfl}^{\mathrm{fl}}$ or G9a ${ }^{-/-}$naive T cells. Data are from 1 representative experiment of 4 experiments $\left(n=5-8\right.$ per experiment). Numbers represent frequency of $C D 4^{+} \mathrm{Foxp} 3^{+}$cells. (E) Cells from the spleen, $\mathrm{mLN}$, and LP of G9a $a^{f / f l}$ or $\mathrm{G9a}^{-/-}$mice were stained for CD4 and these cells analyzed for expression of CD25 and intracellular Foxp3. Representative FACS plots are shown $(n=3-6)$. Numbers represent frequency of CD4+CD25+Foxp3 ${ }^{+}$cells. (F) Proliferation of bead-sorted CD4 ${ }^{+}$CD25- Teff cells from WT mice cultured alone or with the indicated ratios of G9a ${ }^{f l / f l}$ or G9a ${ }^{-/-}$CD4 $4^{+}$CD25 $5^{+}$Tregs in the presence of T cell activator beads for 4 days. Data are representative of 3 independent experiments. ${ }^{* \star} P<0.01$; ${ }^{\star \star \star} P<0.001$. Error bars indicate SEM.

during Th1 and Th2 cell differentiation (34). Although pharmacological inhibition of G9A methyltransferase activity had no effect on Th1 or Th2 cell differentiation, we observed dysregulated expression of IL-17A, suggesting a role for G9A-dependent H3K9me2 in the silencing of IL-17A and potentially regulation of Th17, and by relation, Treg differentiation. Thus, we sought to determine the role of G9A and H3K9me2 in Th17 and Treg lineage development.

Here, we used a $T$ cell transfer model of intestinal inflammation and found that G9A is a negative regulator of both Th17 and Treg differentiation. Following transfer of naive G9A-deficient Th cells, we observed increased Th17 and Treg differentiation and reduced Th1 cell differentiation in the absence of any intestinal inflammation. In contrast with the proposed role of G9A and $\mathrm{H} 3 \mathrm{~K} 9 \mathrm{me} 2$, we did not find that $\mathrm{H} 3 \mathrm{~K} 9 \mathrm{me} 2$ accumulated at lineage-promiscuous loci during Th17 or Treg differentiation. Instead, $\mathrm{H} 3 \mathrm{~K} 9 \mathrm{me} 2$ was present at high levels across lineage-specifying loci (Foxp3, Rorc, and Il17a/f) in naive Th cells, and these levels decreased during Th cell differentiation. Lack of H3K9me2 in naive G9a-deficient ( $\left.G 9 a^{-/-}\right)$Th cells promoted Th17 and Treg differentiation in vitro and in vivo due to enhanced sensitivity to the lineage-promoting cytokine TGF- $\beta 1$. The absence 
A
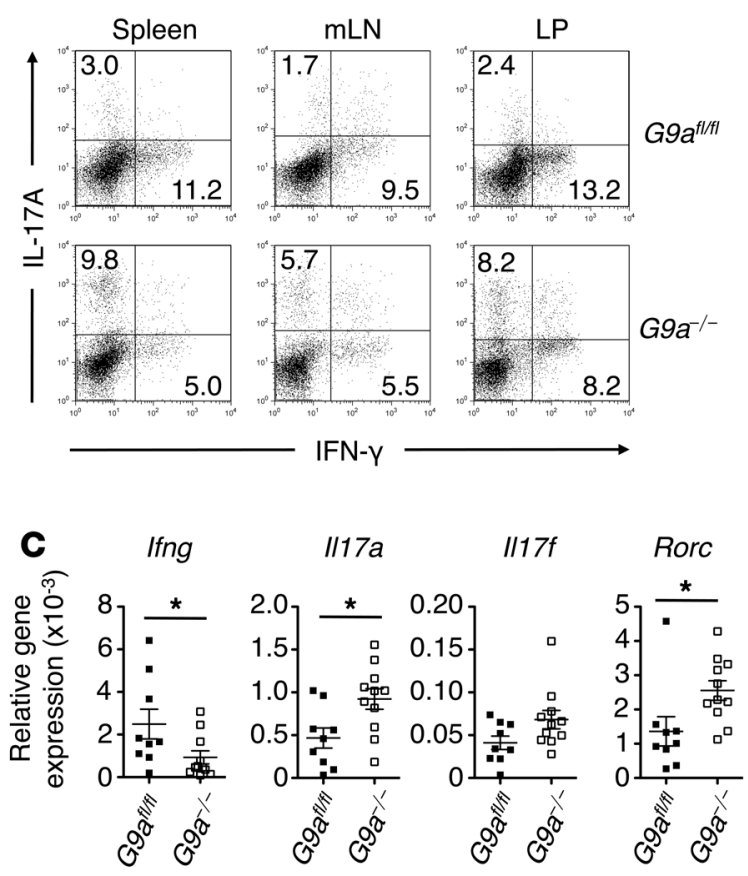
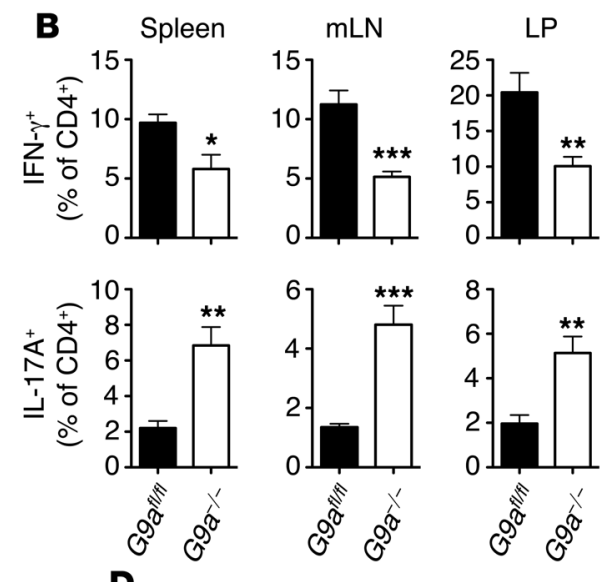

Figure 3

Dysregulated IFN- $\gamma$ and IL-17A production from $\mathrm{Gga}^{-/-}$Th cells after transfer into Rag $1^{-/-}$mice. CD4 ${ }^{+} \mathrm{CD} 25-\mathrm{CD} 45 \mathrm{RB}^{\mathrm{hi}}$ naive $\mathrm{T}$ cells $\left(4 \times 10^{5}\right)$ from $\mathrm{G}^{\mathrm{fflfl}}$ or $\mathrm{G9a}^{-/-}$mice were transferred into Rag $1^{-/-}$mice and analyzed 7 weeks after transfer. (A) Representative IL-17A and IFN- $\gamma$ expression by $\mathrm{CD} 4{ }^{+}$cells. Numbers represent frequency of cells in each quadrant. (B) Quantitative analysis of intracellular IL-17A and IFN- $\gamma$ produced by CD4+ cells in the spleen, mLN, and LP. (C) Quantitative RT-PCR analysis of mRNA transcripts encoding Ifng, II17a, II17f, and Rorc measured in proximal colons and expressed relative to Actb. (D) Serum IFN- $\gamma$ and IL-17A levels. Each point represents an individual mouse and is from 2 of 4 independent experiments $\left(n=5-8\right.$ per experiment). ${ }^{*} P<0.05 ;{ }^{* *} P<0.01$; ${ }^{* *} P<0.001$. Error bars indicate SEM.

of G9A resulted in increased chromatin accessibility at the promoter and CNS1 of the Foxp3 gene. G9A-mediated dimethylation of $\mathrm{H} 3 \mathrm{~K} 9$ served a critical function in limiting Th cell development by raising the threshold for TGF- $\beta 1$-induced activation and controlling access to target genes. Together, these results suggest that G9A is a potential novel therapeutic target for treating IBD.

\section{Results}

G9a is required for the development of $T$ cell-dependent intestinal inflammation. To determine the role of G9A in T cell differentiation in vivo, we used a well-established mouse model of colitis (35). Adoptive transfer of naive $\mathrm{CD}^{+} \mathrm{CD} 25^{-} \mathrm{CD} 45 \mathrm{RB}{ }^{\text {hi }} \mathrm{T}$ cells into lymphopenic $R a g 1^{-/-}$recipients leads to severe colitis that is associated with expansion and accumulation of pathogenic IFN- $\gamma$-producing Th cells that can be regulated by both Th17 and Tregs (35-38). Mice carrying a "floxed" allele of G9a (34) were crossed with mice expressing Cre recombinase under control of CD4 promoter/enhancer elements, resulting in the selective deletion of G9A in both $\mathrm{CD}^{+}$and $\mathrm{CD}^{+} \mathrm{T}$ cells (mice referred to here as $\mathrm{G} \mathrm{a}^{-/-}$mice). As expected, Rag $1^{-/-}$mice that received naive T cells isolated from control G9 $\mathrm{all}^{f / f l}$ mice began to lose weight at 5 weeks after transfer. In contrast, Rag1 $1^{-/-}$mice that received $\mathrm{T}$ cells from $\mathrm{G} 9 \mathrm{a}^{-/-}$mice continued to gain weight similarly to unreconstituted $\operatorname{Rag} 1^{-/-}$mice (Figure $1 \mathrm{~A}$ ). Mice that received control G9aflfl $\mathrm{T}$ cells developed severe inflammation of the colon characterized by crypt hyperplasia, inflammatory cell infiltration, and loss of goblet cells at 7 weeks (Figure 1, B and $\mathrm{C}$ ). In contrast, mice that received $G 9 a^{-1-} \mathrm{T}$ cells failed to display any detectable colonic inflammation and were indistinguishable from unreconstituted $\operatorname{Rag} 1^{-/-}$mice. In addition, $\operatorname{Rag} 1^{-/-}$mice reconstituted with $G 9 a^{f l / f l} \mathrm{~T}$ cells displayed significant colonic shortening and splenomegaly compared with mice reconstituted with $G 9 a^{-/-}$ $\mathrm{T}$ cells (Figure 1, D and E). Other symptoms of inflammation, including elevated levels of serum TNF- $\alpha$, were significantly attenuated in mice receiving $G 9 a^{-1-}$ Th cells (Figure $1 \mathrm{~F}$ ). We failed to detect any significant differences in the frequency of $\mathrm{CD}^{+} \mathrm{T}$ cells in the spleen or mesenteric LNs (mLN) at 7 weeks after transfer (Figure 1G); however, the total number of $\mathrm{CD} 4^{+}$cells was slightly reduced in the spleen. Consistent with decreased intestinal pathology, we observed a lower frequency and number of $G 9 a^{-/-} \mathrm{T}$ cells in the lamina propria (LP) (Figure 1G). Thus, T cell-intrinsic expression of G9a is critical for the development of intestinal inflammation.

G9A inhibits conversion of naive Th cells into Foxp $3^{+}$regulatory T cells. Cotransfer of Foxp $3^{+}$Tregs with naive T cells into Rag $1^{-/-}$mice abrogates the development of colitis (39). As we observed no weight loss or pathology following transfer of $G 9 a^{-/-} \mathrm{T}$ cells, we first examined the conversion of naive $G 9 a^{-/-} \mathrm{T}$ cells into Foxp $3^{+}$Tregs during T cellmediated colitis. Although we could not detect significant conversion of control G9 $a^{f / f l} \mathrm{~T}$ cells in the peripheral blood, we could detect significantly elevated frequencies of Foxp $3^{+}$Tregs as early as 4 weeks after transfer of naive $G 9 a^{-1-}$ T cells (Figure 2, A and B). Furthermore, 7 weeks following adoptive transfer of $G 9 a^{f l / f l} \mathrm{~T}$ cells, we observed that less than $4 \%$ of CD $4^{+} \mathrm{T}$ cells acquired Foxp 3 expression in the spleen, $\mathrm{mLN}$, and large intestinal LP (Figure 2, C and D). In contrast, we identified a 2 - to 10 -fold increase in the frequency of Foxp $3^{+}$Tregs 

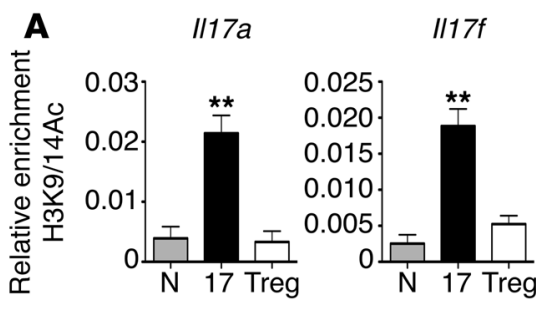

$1117 f$
Rorc

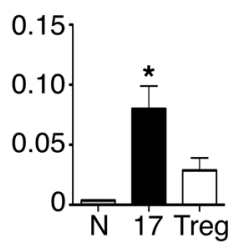

Rorc
Foxp3

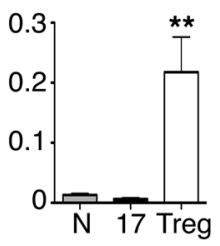

Foxp3
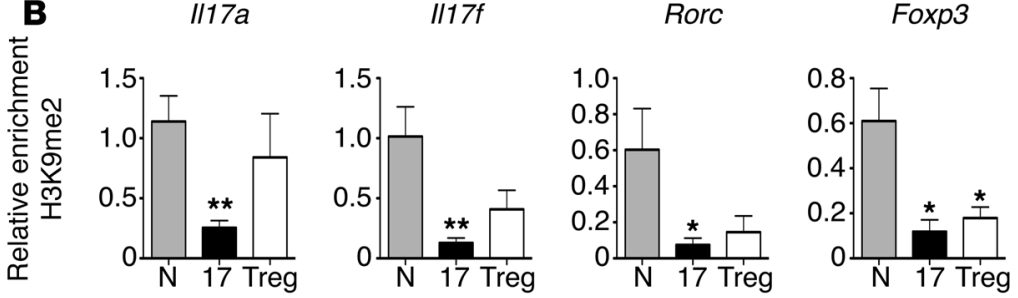

Figure 4

Dynamic regulation of histone acetylation and methylation during Th cell differentiation. Naive CD4+ $T$ cells (N) from WT mice were differentiated in vitro under Th17 (17) or Treg-promoting conditions and processed for ChIP analysis using antibodies specific for (A) H3K9/14Ac or (B) H3K9me2. Quantitative PCR was performed using primers for the promoters of the specific genes. Data shown are from 3 to 5 independent experiments performed in duplicate. Statistics compare differentiated cells to naive. ${ }^{*} P<0.05$; ${ }^{\star \star} P<0.01$. Error bars indicate SEM. in all tissues examined in mice that received $\mathrm{G} 9 \mathrm{a}^{-/-} \mathrm{T}$ cells (Figure 2, $\mathrm{C}$ and D). However, because mice that received $G 9 a^{-1-} \mathrm{T}$ cells had fewer $\mathrm{CD}^{+} \mathrm{T}$ cells (Figure 1G), the total number of Foxp $3^{+}$cells was comparable in mice that received G9 $a^{l / f l}$ and $G 9 a^{-/-} \mathrm{T}$ cells (Figure 2D). Functionally, we failed to observe any differences in the frequency or suppressive capacity of thymus-derived Tregs between G9al/fl and $G 9 a^{-/-}$mice (Figure 2, E and F). However, as sorted G9a $a^{f / f l}$ and $G 9 a^{-1-}$ $\mathrm{CD} 4^{+} \mathrm{CD} 25^{-} \mathrm{CD} 45 \mathrm{RB}^{\text {hi }}$ cells contained approximately $0.5 \%$ thymusderived Tregs (Supplemental Figure 1A; supplemental material available online with this article; doi:10.1172/JCI69592DS1), it remained a possibility that the increased frequency of Foxp $3^{+}$cells in the recipients of $\mathrm{G} 9 a^{-/-} \mathrm{T}$ cells was a result of in vivo expansion of $\mathrm{G} 9 a^{-/-}$Tregs. To address this concern, we transferred purified $\mathrm{CD} 4^{+} \mathrm{CD} 25^{+}$Tregs from $G 9 a^{l / f l}$ and $G 9 a^{-/-}$mice along with WT CD $4{ }^{+} \mathrm{CD} 25^{-} \mathrm{CD} 45 \mathrm{RB}^{\mathrm{hi}}$ $\mathrm{T}$ cells into Rag1 $1^{-/-}$recipients. $\mathrm{CD} 4^{+} \mathrm{CD} 25^{+}$Tregs from either genotype were capable of preventing weight loss (Supplemental Figure 1B). Furthermore, similar frequencies of $G 9 a^{f l f l}$ and $G 9 a^{-1-}$ Foxp $3^{+}$ cells were found in the spleen, $\mathrm{mLN}$, and LP of the recipient mice, indicating that in vivo expansion of Tregs is not affected by loss of G9A (Supplemental Figure 1C). These data suggest that the effects of G9A deficiency were specific for Treg differentiation from naive $T$ cells and that $\mathrm{T}$ cell-intrinsic expression of G9A regulates the development of intestinal inflammation, possibly by limiting the differentiation of Tregs in vivo.

G9a controls Th cell differentiation during colitis. During intestinal inflammation, IFN- $\gamma$ is pathogenic $(4,35,38)$, while the function of IL-17A/F and Th17 cells is controversial, with studies suggesting both pathogenic $(40-42)$ and protective $(37,43)$ roles. We next examined the frequency of Th1 and Th17 cells that developed following transfer of $G 9 a^{f l / f l}$ or $G 9 a^{-1-} \mathrm{CD} 4{ }^{+} \mathrm{CD} 25^{-} \mathrm{CD} 45 \mathrm{RB}^{\text {hi }}$ cells. Consistent with a lack of intestinal inflammation and systemic disease, we detected significantly fewer IFN- $\gamma$-producing $G 9 a^{-/-}$T cells in the spleen, $\mathrm{mLN}$, and LP at 7 weeks after transfer (Figure 3, A and B) as well as significantly decreased expression of Ifng mRNA in the colon (Figure 3C) and significantly reduced levels of IFN- $\gamma$ in the serum (Figure 3D) of $G 9 a^{-/-}$T cell recipients. As we have previously shown that $G 9 a^{-/-} \mathrm{T}$ cells are fully capable of differentiating into Th1 cells and producing IFN- $\gamma$ in vitro as well as in vivo during helminth infection (34), the decreased frequency of IFN- $\gamma$-producing Th1 cells is most likely not due to an intrinsic inability of $G 9 a^{-/-} \mathrm{Th}$ cells to produce IFN- $\gamma$. However, to directly address this possibility, we injected $\mathrm{Rag}^{-/-}$mice that received $\mathrm{G} 9 \mathrm{a}^{-/-} \mathrm{T}$ cells with either IL-12 or IFN- $\gamma$ to promote Th1 cell differentiation. Despite significantly increasing the frequency of IFN- $\gamma$-producing T cells (Supplemental Figure $2 \mathrm{~A}$ ) and reducing the frequency of Foxp $3^{+}$Tregs (Supplemental Figure $2 \mathrm{~B}$ ) in the LP, there was no change in weight loss, gross pathology, colon length, or spleen weight (Supplemental Figure 2, $\mathrm{C}-\mathrm{F})$. These results demonstrate that $\mathrm{G} 9 \mathrm{a}^{-/-} \mathrm{T}$ cells are not inherently deficient in their ability to differentiate into Th 1 cells during $\mathrm{T}$ cell transfer colitis, but do not induce intestinal inflammation.

In contrast to the IFN- $\gamma$-producing Th 1 cells, we observed a significantly increased frequency of IL-17A-producing Th17 cells in the spleen, $\mathrm{mLN}$, and LP of mice that received $G 9 a^{-/-} \mathrm{T}$ cells compared with mice that received control G9 $a^{f l f l} \mathrm{~T}$ cells (Figure 3 , A and B). We also observed significantly increased expression of mRNA of the Th17-specific genes Il17a and Rorc and a modest increase in Il17f in the colon (Figure 3C) as well as heightened serum levels of IL-17A (Figure 3D). Thus, T cell-specific deletion of G9a results in an increased frequency of both Treg and Th17 cells during intestinal inflammation, suggesting that G9a negatively regulates the differentiation of these cell lineages in vivo. Furthermore, these results are consistent with a protective role for Th17 cells in colitis.

As we observed that naive $G 9 a^{-/-} \mathrm{T}$ cells failed to induce intestinal inflammation, we hypothesized that G9a-deficient T cells would influence G9a-sufficient T cells during T cell transfer colitis and protect from disease. Consistent with this, we found that cotransfer of $G 9 a^{-/-} \mathrm{T}$ cells with WT T cells offered significant reduction in intestinal inflammation compared with that in mice receiving WT T cells alone, although weight loss, splenomegaly, or colon length were not significantly different among the groups (Supplemental Figure 3, A-E).

G9A-dependent H3K9me2 is dynamically regulated during Th17 and Treg differentiation. To address how G9A controls Th17 and Treg differentiation, we first examined the expression of activating and inhibitory epigenetic modifications during Th17 and Treg differentiation, focusing on histone $\mathrm{H} 3$ acetylation $(\mathrm{H} 3 \mathrm{~K} 9 / 14 \mathrm{Ac})$ as well as $\mathrm{H} 3 \mathrm{~K} 9 \mathrm{me} 2$, the repressive histone modification mediated by G9A. We employed an in vitro system of Th cell differentiation to generate IL-17A-producing Th17 and Foxp3-expressing Tregs from naive precursors. ChIP analysis of activating H3K9/14Ac modifications revealed increased $\mathrm{H} 3 \mathrm{~K} 9 / 14 \mathrm{Ac}$ at the promoters of lineage-specific genes (Il17a, Il17f, and Rorc in Th17 cells and Foxp3 in Tregs), but not at lineage-promiscuous genes (Il7a, Il17f, and Rorc in Tregs and Foxp3 in Th17 cells) (Figure 4A). This finding is consistent with a role for 

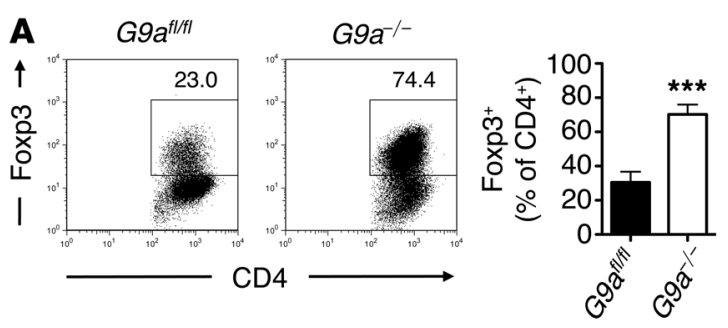

B

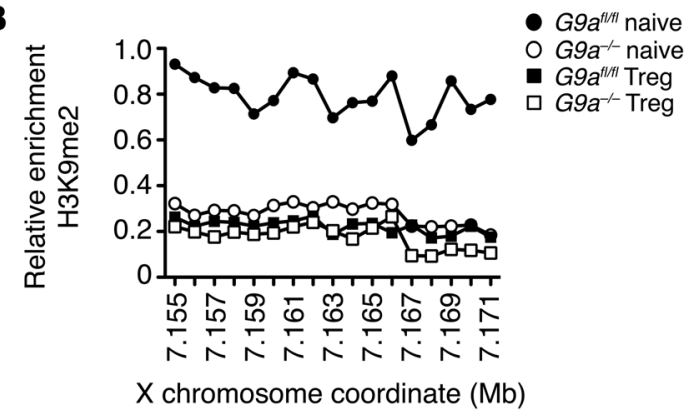

histone acetylation in expression of lineage-specific genes during Th cell differentiation (44). However, in contrast to our expectations, we found that $\mathrm{H} 3 \mathrm{~K} 9 \mathrm{me} 2$ is not acquired at lineage-nonspecific genes during differentiation. Instead, we observed high levels of inhibitory H3K9me2 at the Il17a, Il17f, Rorc, and Foxp3 promoters in naive T cells that decreased following activation under either Th17 or Tregpromoting conditions (Figure 4B). Thus, unlike other repressive marks, such as $\mathrm{H} 3 \mathrm{~K} 27 \mathrm{me} 3$ (24) and H3K9me3 (25), these results demonstrate that G9A-dependent $\mathrm{H} 3 \mathrm{~K} 9 \mathrm{me} 2$ is not acquired at lineage-promiscuous genes in Th17 and Tregs, but instead is found at high levels in naive $\mathrm{T}$ cells and subsequently removed during Th cell activation. This suggests that the role of G9A and H3K9me2 is to limit activation-induced differentiation of naive $\mathrm{T}$ cells into Th17 and Treg fates rather than prevent the expression of lineagepromiscuous genes and nonspecific lineage differentiation.

G9A limits Treg differentiation in vitro. Based on our results, we hypothesized that the absence of G9A would result in enhanced Treg and Th17 cell differentiation in vitro. Following in vitro differentiation of $\mathrm{T}$ cells isolated from $\mathrm{G} 9 \mathrm{afl}^{\mathrm{fl} / \mathrm{fl}}$ and $\mathrm{G} 9 \mathrm{a}^{-/-}$mice, we observed a significantly higher frequency of Foxp3-expressing Tregs (Figure 5A) and IL-17A-producing Th17 cells in the absence of G9A (Supplemental Figure 4A). This increase was the result of enhanced differentiation into Foxp $3^{+}$cells rather than increased

\section{Figure 5}

G9A limits in vitro differentiation of Tregs. (A) Naive CD4+ $T$ cells from $\mathrm{G9a}^{f f / f l}$ or $\mathrm{G9a}^{-/-}$mice were differentiated for 6 days under Treg-promoting conditions and analyzed for Foxp3 expression. Representative flow cytometry data and quantification of Foxp3+ cells $(n=11)$ are shown. Numbers represent frequency of $\mathrm{CD} 4{ }^{+} \mathrm{Foxp} 3^{+}$cells. (B) Naive and in vitro differentiated Tregs from G9a $a^{\text {fl/fl }}$ or $\mathrm{G9a}^{-/-} \mathrm{CD} 4^{+} \mathrm{T}$ cells were processed for ChIP analysis using antibodies specific for H3K9me2. H3K9me2 levels were determined at the Foxp3 locus. Data shown are the mean of 3 independent experiments performed in duplicate. ${ }^{* \star} P<0.001$. Error bars indicate SEM.

proliferation, as the number of divisions observed by CFSE dilution was comparable between $G 9 a^{\text {fl/fl }}$ and $G 9 a^{-/-}$Treg cultures (Supplemental Figure 5). Furthermore, we found that H3K9me2 was enriched across the Foxp 3 loci in naive G9 al/fl $^{\mathrm{T}} \mathrm{T}$ cells but not in G9a $a^{-1-} \mathrm{T}$ cells and, upon Treg differentiation, H3K9me2 levels in G9a $a^{f l f l} \mathrm{~T}$ cells were reduced to levels similar to those of naive $G 9 a^{-/-}$ $\mathrm{T}$ cells (Figure 5B). A similar result was obtained at the $\mathrm{Il17a/flocus}$ under Th17 cell differentiation conditions (Supplemental Figure $4 \mathrm{~B})$. Consistent with our results demonstrating that $\mathrm{H} 3 \mathrm{~K} 9 \mathrm{me} 2$ is not acquired at nonspecific loci, we failed to observe any promiscuous IL-17A production from Tregs or Foxp3 expression in Th17 cells in the absence of G9A (Supplemental Figure 6). These results demonstrate that homeostatic G9A-dependent $\mathrm{H} 3 \mathrm{~K} 9 \mathrm{me} 2$ histone modifications in naive $\mathrm{T}$ cells are critical for limiting the magnitude of Th17 and Treg responses, but are dispensable for repressing lineage-promiscuous genes in Th17 and Tregs.

G9a-deficient T cells display increased sensitivity to TGF- $\beta 1$. Our results demonstrate that lack of G9A is associated with decreased Th1 cell differentiation with coincident increases in Th17 and Treg responses. As TGF- $\beta 1$ has an important role in both limiting IFN- $\gamma$ production $(45,46)$ and promoting Th17/Treg responses $(12-14,16)$, we hypothesized that G9a-deficient T cells would display dysregulated responsiveness to TGF- $\beta 1$ in vitro. First, we cultured naive G9al/fl and $G 9 a^{-/-} \mathrm{T}$ cells under Th 1 cell-polarizing conditions with varying concentrations of TGF- $\beta 1$ to examine the role of G9A in TGF- $\beta 1-$ dependent inhibition of Th1 cell responses. We failed to observe any significant differences in the ability of TGF- $\beta 1$ to inhibit IFN- $\gamma$ production from G9a $a^{f l / f l}$ or $G 9 a^{-/-}$T cells (Figure 6). However, $G 9 a^{-/-}$ Th1 cells treated with varying concentrations of TGF-1 showed significantly increased frequency of Foxp $3^{+}$cells compared with G9al/fl T cells, especially at low concentrations of TGF- $\beta 1$ (Figure 6$)$. Thus, G9A is dispensable for TGF- $\beta 1-$ dependent inhibition of IFN- $\gamma$.

\section{Figure 6}

Enhanced TGF- $\beta 1$ sensitivity of $\mathrm{Gga}^{-/-} \mathrm{T}$ cells results in increased Foxp3+ cells under Th1 conditions. G9a fl/fl or $\mathrm{G} \mathrm{a}^{-/-}$naive $\mathrm{CD} 4^{+}$cells were differentiated under Th1 cellpromoting conditions with the indicated dose of TGF- $\beta 1$ and analyzed at day 6 for the expression of IFN- $\gamma$ and Foxp3 by flow cytometry. Data shown are representative of at least 3 independent experiments. Numbers represent frequency of cells in each quadrant.
TGF- $\beta 1(\mathrm{ng} / \mathrm{ml})$

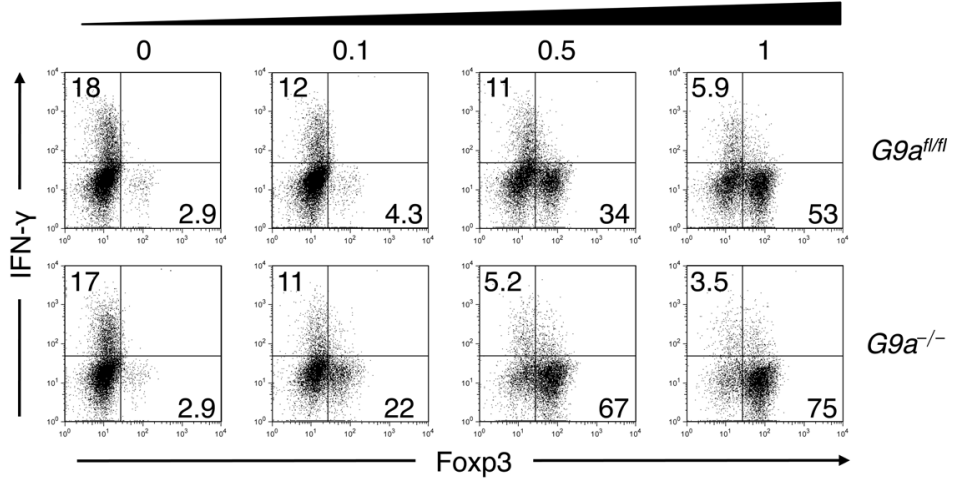


A
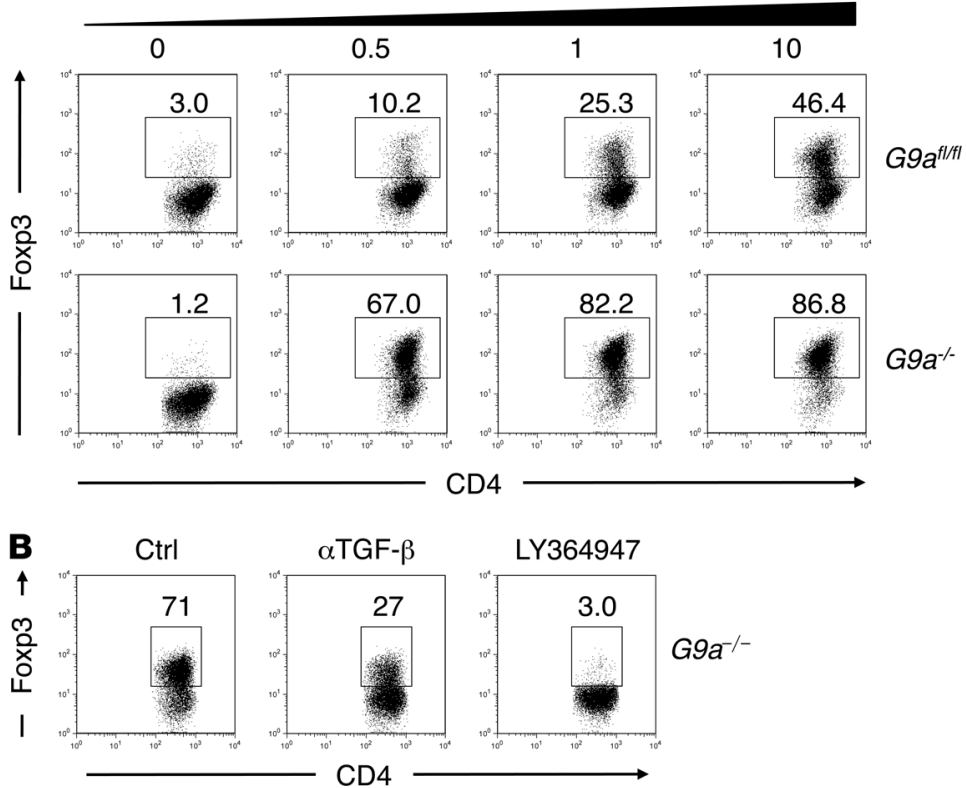

Figure 7

Enhanced sensitivity to TGF- $\beta 1$ leads to increased Tregs from G9a ${ }^{-/-}$T cells. (A) $\mathrm{G9a}^{\mathrm{fl} / \mathrm{fl}}$ or $\mathrm{G9} \mathrm{a}^{-/-}$naive CD4+ cells were differentiated under Treg-promoting conditions with the indicated dose of TGF- $\beta 1$ and analyzed at day 6 for the expression of Foxp3 by flow cytometry. Numbers represent frequency of CD4+Foxp3+ cells. (B) Naive $\mathrm{Gga}^{-/-} \mathrm{T}$ cells were differentiated under Treg-promoting conditions in the presence of vehicle, neutralizing antibody to TGF- $\beta 1(10 \mu \mathrm{g} / \mathrm{ml})$, or TGF- $\beta$ signaling inhibitor (LY364947, $5 \mu \mathrm{M}$ ). Data shown are representative of at least 3 independent experiments. Numbers represent frequency of $\mathrm{CD}^{+}{ }^{+} \mathrm{Foxp} 3^{+}$cells.

TGF- $\beta 1$ is also critical for the differentiation of both Th17 and Treg populations. We next tested whether the absence of G9Adependent $\mathrm{H} 3 \mathrm{~K} 9 \mathrm{me} 2$ would affect TGF- $\beta 1$ responsiveness. We activated naive $G 9 a^{f l f l}$ and $G 9 a^{-/-} \mathrm{T}$ cells under Treg-polarizing conditions with varying concentrations of TGF- $\beta 1$. In the absence of TGF- $\beta 1$, we did not observe Treg differentiation from either G9a-sufficient or G9a-deficient Th cells (Figure 7A), demonstrating that TGF- $\beta 1$ is critically required for Foxp 3 expression in Th cells even in the absence of G9a-dependent H3K9me2. Under Tregpromoting conditions, we found that $G 9 a^{-/-}$Th cells differentiated into Foxp $3^{+}$Tregs at TGF- $\beta 1$ concentrations at least 20 -fold lower than those required for WT cells (Figure 7A). Similar results were obtained under Th17 conditions, where we observed increased frequencies of IL-17A-producing $\mathrm{G} 9 \mathrm{a}^{-/-}$Th cells at all concentrations of TGF- $\beta 1$ (Supplemental Figure 7A). These effects were directly due to TGF- $\beta 1$, as treatment of $G 9 a^{-/-}$Treg (Figure 7B) and Th17 (Supplemental Figure 7B) cell cultures with a neutralizing TGF- $\beta 1$ antibody ( $\alpha$ TGF- $\beta 1$ ) or a chemical inhibitor of TGF- $\beta$ signaling (LY364947) significantly reduced the frequency of Tregs and Th17 cells. These results demonstrate that lack of G9A lowers the threshold for TGF- $\beta 1$-induced generation of Th17 and Tregs. This increased responsiveness was not due to increased TGF- $\beta$ receptor expression or signal strength, as we found no differences in surface expression of TGF- $\beta$ RII (Supplemental Figure 8A) or mRNA levels of Tgfbr2 or Smad3 (Supplemental Figure 8B) between naive G9allfl or $G 9 a^{-1-}$ Th cells. In addition, phosphorylation of Smad3 during Treg differentiation was unaffected by the absence of G9A
(Supplemental Figure 8C). Thus, these results demonstrate that G9A controls TGF- $\beta 1$ responsiveness and subsequent Th cell differentiation.

Methyltransferase activity of G9A is required to limit Treg differentiation. Several studies have demonstrated that G9A has methyltransferase-dependent and methyltransferase-independent functions $(34,47-49)$. To test the role of the methyltransferase activity of G9a in Treg differentiation, we activated WT T cells in the absence or presence of the G9A-specific inhibitors UNC0638 (50) or BIX01294 (51). Similar to results obtained using Th cells from $\mathrm{G} \mathrm{a}^{-/-}$mice, both UNC0638 and BIX01294 treatment resulted in increased frequencies of Foxp3expressing cells (Figure 8). Treatment of $69 a^{-/-} \mathrm{T}$ cells with UNC0638 and BIX01294 during Treg differentiation had no effect (Supplemental Figure 9), demonstrating the specificity of these compounds. Importantly, culture of human peripheral blood-derived $\mathrm{T}$ cells in the presence of UNC0638 led to a significant increase in Foxp3-expressing cells (Supplemental Figure 10), identifying a conserved pathway that regulates Treg differentiation. Similar results were obtained under Th17 conditions, with increased frequencies of IL-17A-producing $\mathrm{CD}^{+}$cells generated in the presence of a G9A inhibitor (Supplemental Figure 11). Taken together, our data indicate that G9A methyltransferase activity in naive $\mathrm{T}$ cells is a negative regulator of Th17 and Treg differentiation.

$G 9 A$ regulates chromatin accessibility and controls epigenetic activation of the Foxp3 locus. In the absence of G9A-dependent H3K9me2, we observed enhanced sensitivity to TGF- $\beta 1$, increased Th17 and Treg differentiation, and protection from $\mathrm{T}$ cell transfer colitis. As G9A-dependent H3K9me2 is lost during Th cell activation, we hypothesized that the absence of G9A and H3K9me2 was leading to increased Th17 and Treg differentiation by controlling early activation of lineage-determining loci. To test this, we examined the epigenetic activation of the Foxp3 locus at an earlier time point during Treg differentiation. We observed increased levels of the activating H3K9/14ac mark at the promoter and CNS1 of the Foxp3 locus in G9a-/- Th cells at day 4 after activation, while $G 9 a^{f / f l}$ Th cells displayed minimal enrichment of H3K9/14Ac (Figure 9A). We also observed increased H3K9/14Ac enrichment at the Foxp 3 locus following stimulation with low levels of TGF- $\beta 1$ (Figure 9B). These results suggest that G9A-dependent $\mathrm{H} 3 \mathrm{~K} 9 \mathrm{me} 2$ directly or indirectly affects the epigenetic activation of the Foxp3 locus. We postulated that the lack of repressive histone modifications would affect chromatin accessibility and subsequent activation of the lineage-specifying loci. To directly test this, we employed a genome-wide sequencing technique (formaldehydeassisted isolation of regulatory elements [FAIRE-Seq]) that measures chromatin accessibility by depleting nucleosome-rich areas of DNA $(52,53)$. Following examination of the Foxp3 locus in naive G9aflfl Th cells, we found much fewer nucleosome-free accessible sites (Figure 9C). In naive $G 9 a^{-/-}$Th cells, we observed increased regions of open chromatin throughout the Foxp3 gene. Critically, there was a specific enrichment of chromatin accessibility surrounding the promoter and CNS1 in naive $G 9 a^{-/-}$Th cells, sites directly associated with the differentiation of TGF- $\beta 1$-induced Tregs (54). These results suggest that, in the absence of G9A, there is an increase in chromatin accessibility that leads to enhanced activation of the Foxp3 locus, resulting in increased frequencies of Tregs. 

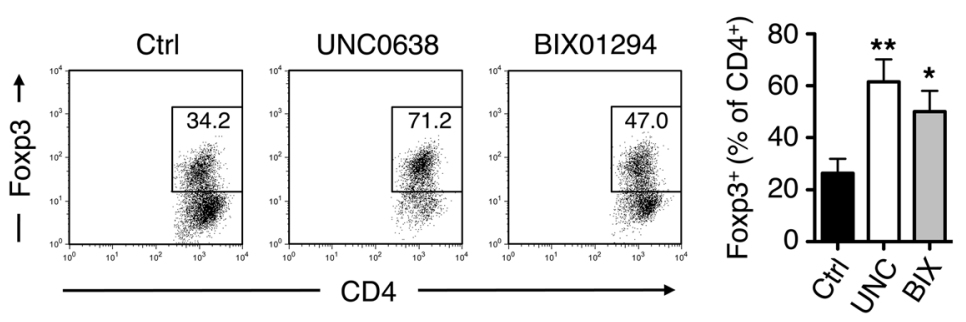

\section{Figure 8}

The methyltransferase activity of G9A is required to dampen Treg generation. Naive CD4+ T cells from C57BL/6 mice were differentiated under Treg-promoting conditions for 6 days in the absence (ctrl) or presence of the G9A-specific inhibitors UNC0638 (UNC, $n=5$ ) or BIX01294 (BIX, $n=8)$ and analyzed by flow cytometry for the expression of CD4 and Foxp3. Numbers represent frequency of $C D 4+F o x p 3+$ cells. ${ }^{*} P<0.05$; ${ }^{\star \star} P<0.01$. Error bars indicate SEM.

\section{Discussion}

Here we identify a central role for a repressive epigenetic modification in the lineage specification of Th17 and Tregs that directly regulates the pathogenesis of $\mathrm{T}$ cell-dependent intestinal inflammation. Although G9A-dependent H3K9me2 is traditionally associated with repression of lineage-promiscuous genes during cell differentiation, we show that in Th17 and Tregs, H3K9me2 acts by controlling chromatin accessibility and responsiveness to the lineage-specifying cytokine TGF- $\beta 1$ and contributes to $T$ cell-mediated colitis by limiting the generation of Th17 and Tregs.

In Th17 and Treg lineages, which are both regulated by TGF- $\beta 1$ signaling, G9A maintains H3K9me2 at high levels in naive T cells. This epigenetic regulatory modification is critical to controlling the magnitude of the Th cell response by limiting access of transcriptional activators to the chromatin. Upon activation, $\mathrm{H} 3 \mathrm{~K} 9 \mathrm{me} 2$ is removed

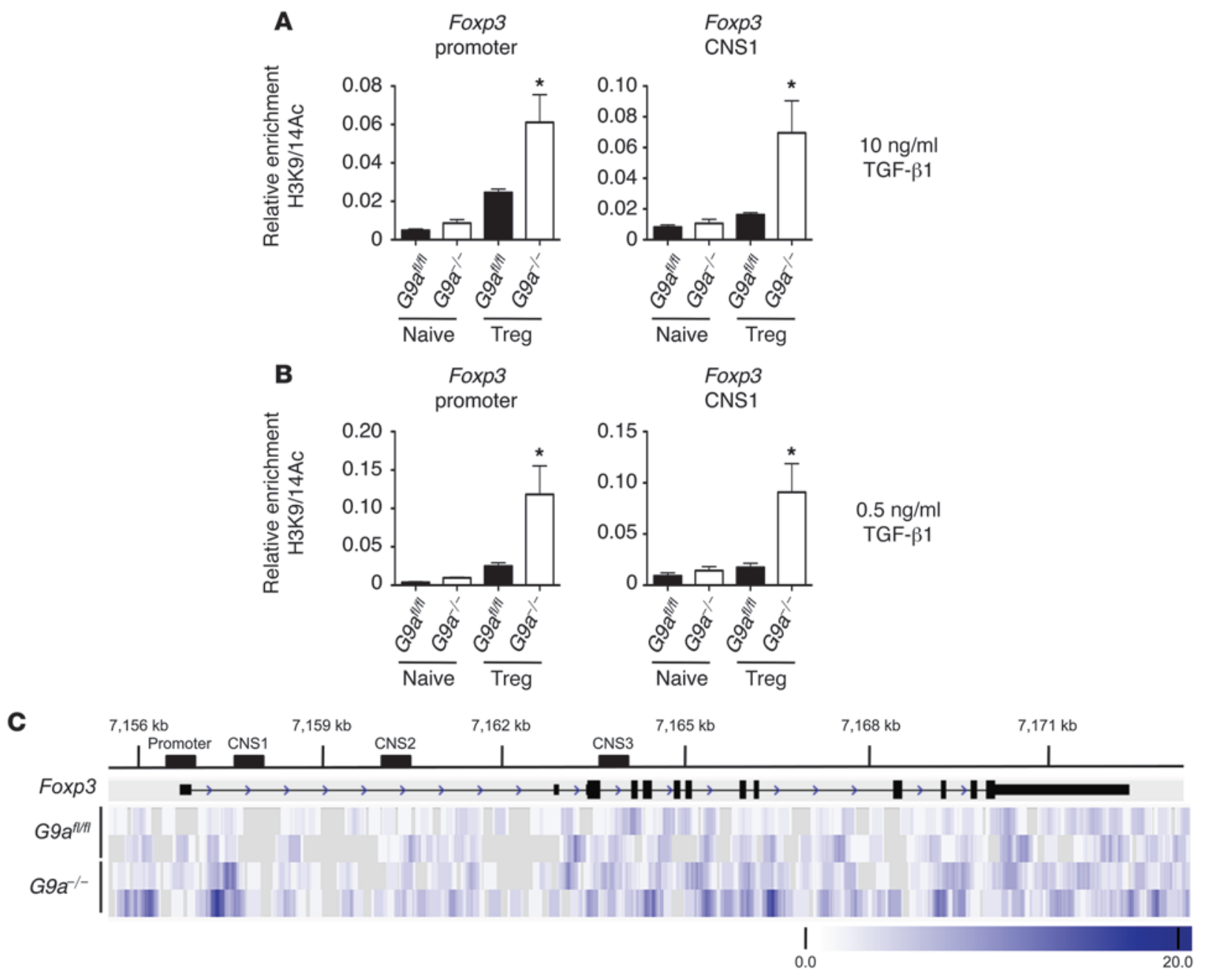

Figure 9

Increased activation of the Foxp3 locus in the absence of G9A. G9a flffl $_{\text {or }} \mathrm{G9a}^{-/-}$naive CD4 ${ }^{+}$cells were differentiated under Treg-promoting conditions for 4 days with (A) $10 \mathrm{ng} / \mathrm{ml} \mathrm{TGF- \beta 1}$ and (B) $0.5 \mathrm{ng} / \mathrm{ml} \mathrm{TGF-} \beta 1$ and analyzed by ChIP for H3K9/14Ac levels at the Foxp3 promoter and Foxp3 CNS1. (C) Naive CD4+CD25-CD45RB hi cells from G9a ${ }^{\text {flfll }}$ or G9a-/- mice were subjected to FAIRE-seq and data analyzed at the Foxp3 locus. Schematic depicts the Foxp3 gene with locations along the $\mathrm{X}$ chromosome and approximate locations of the promoter and 3 CNS. Data shown are the mean from 2 to 3 independent experiments performed in duplicate. ${ }^{*} P<0.05$. Error bars indicate SEM. 
nonspecifically by a yet-to-be-determined $\mathrm{H} 3 \mathrm{~K} 9 \mathrm{me} 2$ demethylase. Importantly, the loss of $\mathrm{H} 3 \mathrm{~K} 9 \mathrm{me} 2$ is not sufficient to induce gene expression and lineage commitment. Activation of gene expression via acetylation of $\mathrm{H} 3 \mathrm{~K} 9 / 14$ at lineage-specific genes, most likely in concert with lineage-specifying transcription factors downstream of cytokine signaling, drives lineage commitment. In the absence of G9A-dependent $\mathrm{H} 3 \mathrm{~K} 9 \mathrm{me} 2$, the threshold of activation by TGF- $\beta 1$ is substantially lower due to increased accessibility of transcriptional machinery to lineage-specifying loci, resulting in increased frequencies of Th17 and Tregs. Thus, our results identify a role for repressive epigenetic modifications in Th cell differentiation.

Exactly how the lack of G9A-dependent H3K9me2 leads to increased chromatin accessibility is unknown. However, it has been shown that chromatin domains enriched in G9A-dependent $\mathrm{H} 3 \mathrm{~K} 9 \mathrm{me} 2$ are found predominantly at the nuclear lamina where accessibility and gene expression is limited $(55,56)$. Thus, the loss of $\mathrm{H} 3 \mathrm{~K} 9 \mathrm{me} 2$ may result in more accessible chromatin by impairing chromatin-lamina interactions. Another possibility is that in some cell types, $\mathrm{H} 3 \mathrm{~K} 9 \mathrm{me} 2$ modifications are intimately linked with DNA methylation (57-59). In the absence of G9A, decreased levels of $\mathrm{H} 3 \mathrm{~K} 9 \mathrm{me} 2$ may cause a concomitant reduction in DNA methylation and reduction of inhibitory methylated DNA-binding proteins (60). Future studies will dissect the molecular mechanisms of G9A-dependent regulation of chromatin accessibility.

We have previously shown that following infection with the intestinal helminth parasite Trichuris muris, G9a-deficient Th cells fail to develop into protective Th2 cells and instead differentiate into nonprotective Th1 cells (34). Therefore, the failure of G9adeficient Th cells to cause intestinal inflammation is most likely not due to an inherent defect in their ability to develop into pathogenic IFN-producing Th1 cells. However, it remains possible that G9A is required for optimal pathogenicity of T cells in this model. In addition, we show that, following transfer of $G 9 a^{-/-} \mathrm{T}$ cells, treatment with IL-12 or IFN- $\gamma$ significantly enhanced IFN- $\gamma$ production. However, since this treatment does not result in increased disease, other factors such as increased frequencies of Tregs that are maintained after treatment may continue to modulate disease progression. We also showed that G9A-deficient Th cells were unable to confer resistance to the development of intestinal inflammation induced by WT Th cells. These results suggest that the effects of $G 9 a$ deletion are cell intrinsic and that $G 9 a^{-/-}$Th cells are likely not producing soluble factors that can directly tolerize or promote a regulatory phenotype in G9a-sufficient Th cells.

Many studies of repressive histone modifications, including $\mathrm{H} 3 \mathrm{~K} 9 \mathrm{me} 2$, have focused on the increase in repressive modifications to prevent gene transcription of lineage-promiscuous genes rather than decreased methylation at lineage-specific sites to allow gene transcription. In Th cells, however, loss of repression has been shown to facilitate lineage-specific differentiation. For example, expression of growth factor independent 1 (Gfi1), a transcriptional repressor that has been shown to interact with G9A (61), has been found to decrease with TGF- $\beta$-induced activation of T cells and is important for limiting IL-17A production and Treg generation (62). Recently, T cell activation was found to cause rapid degradation of Argonaute2 (Ago2), a component of the miRNA-induced silencing complex. Naive T cells with reduced Ago 2 and miRNA expression differentiated more readily into cytokine-producing Th cells (63). This suggests that removal of repression via activationinduced miRNA downregulation promotes acquisition of Th cell effector functions. Our results demonstrate that loss of repressive histone modifications is another critical component of Th cell differentiation and most likely acts in parallel with these previously established mechanisms.

Inhibition of G9A activity by the small molecule inhibitors UNC0638 and BIX01294 resulted in enhanced Th17 and Treg differentiation. From this result, we conclude that G9A-mediated histone methylation is a dynamic process that requires continued G9A enzymatic activity to maintain $\mathrm{H} 3 \mathrm{~K} 9 \mathrm{me} 2$ and points to a role for a demethylase in the steady-state maintenance as well as the activation-induced removal of $\mathrm{H} 3 \mathrm{~K} 9 \mathrm{me} 2$. Nine lysine demethylases have been shown to demethylate H3K9me2 (22), and the identification of the demethylase(s) that regulate(s) H3K9me2 in differentiating Th17 and Tregs may provide a novel inhibitory target to reduce the differentiation of these lineages in vivo. As the induction of Tregs has been shown to antagonize anticancer therapies (64), reduction of this population during chemo- or immunotherapy may enhance treatment efficacy.

Intriguingly, the role of G9A and $\mathrm{H} 3 \mathrm{~K} 9 \mathrm{me} 2$ is distinct from the role of Suv39h1/2-dependent H3K9me3-repressive modifications in Th2 cells, where acquisition of $\mathrm{H} 3 \mathrm{~K} 9 \mathrm{me} 3$ at the Ifng locus is critical for gene silencing and Th2 cell lineage stability (25). Further, we previously demonstrated that Th1 and Th2 cell differentiation are independent of G9A enzymatic activity (34), suggesting that the epigenetic mechanisms that regulate Th17 and Treg differentiation are fundamentally different from those that regulate Th1 and Th2 cells. Why distinct Th cell subsets employ different epigenetic mechanisms to control lineage differentiation and stability remains unclear. Our results suggest that modulation of G9Adependent $\mathrm{H} 3 \mathrm{~K} 9 \mathrm{me} 2$ may be used to manipulate the balance of Th cell subsets and that "epigenetic therapy" (65) may prove useful in the treatment of IBD and other autoimmune or autoinflammatory diseases associated with dysregulated Th17 and Treg responses.

\section{Methods}

Mice. The generation of G9 $a^{f / f l}$ mice has been described (34). CD4-Cre mice were obtained from Taconic. Rag $1^{-/-}$mice were obtained from Jackson Laboratory. Animals were maintained in a specific pathogen-free environment.

ChIP. ChIP for H3K9me2 and H3K9/14Ac was conducted as previously described (66) using $2 \mu \mathrm{g}$ of antibody specific to H3K9me2 (ab1220, Abcam) or H3K9/14Ac (06-599, Millipore). After washing, elution, and reversion of crosslinks, the DNA was isolated and used in quantitative PCR (qPCR) reactions on a real-time PCR system (ABI 7900 Fast). Data are presented as the ratio of immunoprecipitated to input $\mathrm{Ct}$ values. The primers used for PCR analysis of the Il17a/flocus (67) and Foxp3 locus (54) were previously described. Primers for Rorc promoter were as follows: forward, $5^{\prime}$-ATTCCATGAGGGCTTGCCT-3'; reverse, 5'-ACCTGTCATCAGCCTCCCATA-3'.

Induction of T cell transfer colitis. $\mathrm{CD} 4^{+}$cells were enriched from spleens and peripheral LNs (pLNs) of $G 9 a^{f / f l}$ or $G 9 a^{-/-}$mice with a RoboSep cell separator (StemCell Technologies), and stained with anti-CD4, anti-CD25 and antiCD45RB. Naive $\mathrm{CD}^{+} \mathrm{CD} 25^{-} \mathrm{CD} 45 \mathrm{RB}^{\text {hi }}$ cells were purified by cell sorting (FACS DiVA, BD Bioscience). CD $4^{+} \mathrm{CD} 25^{-} \mathrm{CD} 45 \mathrm{RB}^{\text {hi }}$ naive T cells $\left(4 \times 10^{5}\right)$ were injected intraperitoneally into age-matched male Rag $1^{-1-}$ mice, which were monitored for weight loss and sacrificed by $\mathrm{CO}_{2}$ asphyxiation 7 weeks after initiation of the experiment. Blood was obtained by saphenous vein bleeds at the indicated time points.

At the time of sacrifice, mouse colons were removed and flushed with PBS, and the length was measured from the rectum to the cecum. Sections of the proximal and distal colon were fixed in $10 \%$ buffered formalin and stained with H\&E. Gross and histological inflammation were scored on a scale of 0 to 4 , where 0 represented a normal colon and 4 represented 
severe colitis. Adjacent tissue was collected for RNA isolation and used for RT-PCR. Serum was collected, and protein concentration of IL-17, IFN- $\gamma$, and TNF- $\alpha$ were measured by cytometric bead array (BD Biosciences).

Cell culture. $\mathrm{CD}^{+} \mathrm{T}$ cells were isolated from spleen and LNs by negative selection using RoboSep (StemCell Technologies Inc). Then 3 to $4 \times 10^{5}$ $\mathrm{CD} 4{ }^{+}$cells were cultured for 4 to 6 days in DMEM supplemented with $10 \%$ heat-inactivated FBS, $2 \mathrm{mM}$ glutamine, $100 \mathrm{U} / \mathrm{ml}$ penicillin, $100 \mu \mathrm{g} / \mathrm{ml}$ streptomycin, $25 \mathrm{mM}$ Hepes, and $5 \times 10^{-5} \mathrm{M} 2-\mathrm{ME}$ with $1 \mathrm{\mu g} / \mathrm{ml}$ each platebound anti-CD3 (145-2C11) and anti-CD28 (37.51) in the presence of IL-6 (20 ng/ml), IL-23 (10 ng/ml), TGF- $\beta 1$ ( $1 \mathrm{ng} / \mathrm{ml})$, TNF- $\alpha(10 \mathrm{ng} / \mathrm{ml}), \mathrm{IL}-1 \beta$ $(10 \mathrm{ng} / \mathrm{ml})$, anti-IFN- $\gamma(10 \mu \mathrm{g} / \mathrm{ml})$, and anti-IL-4 $(10 \mu \mathrm{g} / \mathrm{ml})$ for Th17-promoting conditions, in the presence of IL- $2(10 \mathrm{ng} / \mathrm{ml})$ and TGF- $\beta 1(10 \mathrm{ng} / \mathrm{ml})$ for Treg-promoting conditions, or in the presence of IL-2 (10 ng/ml), IL-12 $(10 \mathrm{ng} / \mathrm{ml})$, and anti-IL-4 $(10 \mu \mathrm{g} / \mathrm{ml})$ for Th1-promoting conditions. In some cases, cells were plated as above in the presence of $1 \mu \mathrm{M}$ UNC0638, $0.5 \mu \mathrm{M}$ BIX01294, $5 \mu \mathrm{M}$ LY364947 (Sigma-Aldrich), or $10 \mu \mathrm{g} / \mathrm{ml}$ antiTGF- $\beta$. For colitis mice, the spleen, $\mathrm{mLN}$, and LP cells were harvested and plated with $1 \mu \mathrm{g} / \mathrm{ml}$ plate bound anti-CD3 and $1 \mu \mathrm{g} / \mathrm{ml}$ soluble anti-CD28 for 16 to 18 hours with the addition of $50 \mathrm{ng} / \mathrm{ml} \mathrm{PMA}$ and $750 \mu \mathrm{g} / \mathrm{ml}$ ionomycin in the presence of $10 \mu \mathrm{g} / \mathrm{ml}$ brefeldin A for the final 4 to 5 hours.

Human T cell differentiation. CD4 ${ }^{+} \mathrm{T}$ cells were isolated with RosetteSep (StemCell Technologies Inc.), and $\mathrm{CD}^{+} \mathrm{CD} 45 \mathrm{RA}^{+} \mathrm{CD} 45 \mathrm{RO}^{-} \mathrm{CD} 25^{-}$naive conventional $T$ cells were FACS sorted using a BD FACSAria. The purified cells were then activated with artificial antigen-presenting cells and soluble anti-CD3 $(100 \mathrm{ng} / \mathrm{ml})(68)$ in the presence of IL-2 $(300 \mathrm{U} / \mathrm{ml})$ and the indicated concentration of the G9a inhibitor UNC0638 for 13 to 14 days.

Isolation of leukocyte subpopulations and cytokine analysis. Cell suspensions were prepared from the spleen, $\mathrm{mLNs}$, peripheral LN (pLN), thymus, and LP. Fluorescently labeled antibodies to CD4 and CD25 were from eBioscience. For intracellular cytokine staining, cells were cultured for 4 to 6 hours with $50 \mathrm{ng} / \mathrm{ml}$ PMA and $750 \mathrm{ng} / \mathrm{ml}$ ionomycin in the presence of $10 \mu \mathrm{g} / \mathrm{ml}$ brefeldin A (all from Sigma-Aldrich), stained with a fixable viability dye (eBioscience), stained for CD4, fixed, and permeabilized in buffers from a Foxp3-staining kit (eBioscience). Cells were then stained with anti-IL-17a, anti-IFN- $\gamma$, and anti-Foxp3 (eBioscience).

In vitro suppression assay. To measure suppression, $\mathrm{WT} \mathrm{CD} 4^{+} \mathrm{CD} 25^{-}$effector $\mathrm{T}$ cells (Teff cells) were isolated by negative selection (StemCell Technologies), followed by CD25 depletion (Miltenyi Biotec), and stained with CFSE. Teff cells $\left(7 \times 10^{4} /\right.$ well $)$ were stimulated with Dynabeads, mouse T-activator CD3/CD28 (Invitrogen), and varying numbers of Tregs isolated from G9a/f/fl or $G 9 a^{-/-}$mice $\left(0-7 \times 10^{4}\right.$ cells per well). Proliferation was measured 4 days later as CFSE dilution by flow cytometry.

Quantitative RT-PCR. Intestinal tissue was homogenized using a TissueLyser (QIAGEN). RNA was extracted using Trizol (Invitrogen) and reverse transcribed. Gene expression was analyzed by quantitative real-time PCR with SYBR green chemistry (Fermentas) on a real-time PCR system (7900 Fast, Applied Biosystems). The primers used were obtained from QIAGEN or synthesized de novo: $I l 17$ a forward 5'-AGCAGCGATCATCCCTCAAAG-3' and reverse $5^{\prime}$-TCACAGAGGGATATCTATCAGGGTC-3'; Foxp3 forward 5'-CCCAGGAAAGACAGCAACCTT-3' and reverse 5'-TTCTCACAACCAGGCCACTTG-3'.
FAIRE-seq. FAIRE-seq was performed as previously described $(53,69)$. Sequencing was performed on a HiSeq2000. Analysis was performed using BOWTIE, and the MACS peak-calling algorithm was used to generate the signal files.

Statistics. Results represent the mean \pm SEM. Statistical significance was determined by 2-tailed Student's $t$ test using Prism 5.0 (GraphPad Software Inc). A $P$ value of less than 0.05 was considered significant.

Study approval. All mouse experiments were performed at the University of British Columbia in accordance with institutional guidelines and Canadian Council on Animal Care guidelines. All animal studies were approved by the University of British Columbia Committee on Animal Care. Peripheral blood was obtained from healthy volunteers who gave written informed consent in accordance with protocols approved by the University of British Columbia Clinical Research Ethics Board.

\section{Acknowledgments}

This work was supported by the Canadian Institutes of Health Research (CIHR) Canadian Epigenetics, Environment and Health Research Consortium (grant 128090 to C.H. Arrowsmith, M. Lupien, and C. Zaph), CIHR operating grants (MOP-115199 to M.K. Levings, MOP-84545 to K.M. McNagny, MOP-119559, and MOP89773, MOP-106623, and MOP-133493 to C. Zaph), GenomeBC (C37BOW to C. Zaph) and a Canada Foundation for Innovation grant (to C. Zaph). The development of the mouse strains used in this study was supported by funds from the Leon Judah Blackmore Foundation (to F.M.V. Rossi). F. Antignano is the recipient of a CIHR/Canadian Association of Gastroenterology/Crohn's and Colitis Foundation of Canada postdoctoral fellowship. M.J. Oudhoff is the recipient of CIHR/CAG/Janssen Inc. and Michael Smith Foundation for Health Research (MSFHR) postdoctoral fellowships. K.M. McNagny is an MSFHR Senior Scholar. C. Zaph is an MSFHR Career Investigator. M. Lupien is a recipient of a CIHR New Investigator Salary Award and the OICR New Investigator Award. C.H. Arrowsmith holds a Canada Research Chair in Structural Genomics. The SGC is a registered charity number 1097737) that receives funds from AbbVie, Boehringer Ingelheim, the Canada Foundation for Innovation, the Canadian Institutes for Health Research, Genome Canada (through the Ontario Genomics Institute, OGI-055), GlaxoSmith-Kline, Janssen, Lilly Canada, the Novartis Research Foundation, the Ontario Ministry of Economic Development and Innovation, Pfizer, Takeda, and the Wellcome Trust (092809/Z/10/Z).

Received for publication February 27, 2013, and accepted in revised form January 23, 2014.

Address correspondence to: Colby Zaph, The Biomedical Research Centre, Department of Pathology and Laboratory Medicine, 2222 Health Sciences Mall, Vancouver, British Columbia, V6T 1Z3, Canada. Phone: 604.822.7231; Fax: 604.822.7815; E-mail: colby@ brc.ubc.ca.
1. Xavier RJ, Podolsky DK. Unravelling the pathogenesis of inflammatory bowel disease. Nature. 2007; 448(7152):427-434.

2. Jostins L, et al. Host-microbe interactions have shaped the genetic architecture of inflammatory bowel disease. Nature. 2012;491(7422):119-124.

3. Ostanin DV, et al. T cell transfer model of chronic colitis: concepts, considerations, and tricks of the trade. Am J Physiol Gastrointest Liver Physiol. 2009; 296(2):G135-G146.
4. Powrie F, Coffman RL, Correa-Oliveira R. Transfer of $\mathrm{CD}^{+} \mathrm{T}$ cells to C.B-17 SCID mice: a model to study Th1 and Th2 cell differentiation and regulation in vivo. Res Immunol. 1994;145(5):347-353.

5. Strober W, Fuss IJ, Blumberg RS. The immunology of mucosal models of inflammation. Annu Rev Immunol. 2002;20:495-549.

6. Asseman C, Fowler S, Powrie F. Control of experimental inflammatory bowel disease by regulatory T cells. Am J Respir Crit Care Med. 2000;
162(4 pt 2):S185-S189.

7. Singh B, et al. Control of intestinal inflammation by regulatory T cells. Immunol Rev. 2001;182:190-200.

8. Mottet C, Uhlig HH, Powrie F. Cutting edge: cure of colitis by $\mathrm{CD} 4^{+} \mathrm{CD} 25^{+}$regulatory T cells. J Immunol. 2003;170(8):3939-3943.

9. Maloy KJ, Antonelli LR, Lefevre M, Powrie F. Cure of innate intestinal immune pathology by $\mathrm{CD} 4{ }^{+} \mathrm{CD} 25^{+}$regulatory $\mathrm{T}$ cells. Immunol Lett. 2005; 97(2):189-192. 
10. Zhu J, Yamane H, Paul WE. Differentiation of effector CD4 T cell populations. Annu Rev Immunol. 2010; 28:445-489.

11. Littman DR, Rudensky AY. Th17 and regulatory T cells in mediating and restraining inflammation. Cell. 2010;140(6):845-858.

12. Mangan PR, et al. Transforming growth factor- $\beta$ induces development of the Th17 lineage. Nature. 2006;441(7090):231-234.

13. Bettelli E, et al. Reciprocal developmental pathways for the generation of pathogenic effector Th17 and regulatory T cells. Nature. 2006;441(7090):235-238.

14. Veldhoen M, Hocking RJ, Atkins CJ, Locksley RM, Stockinger B. TGF $\beta$ in the context of an inflammatory cytokine milieu supports de novo differentiation of IL-17-producing T cells. Immunity. 2006; 24(2):179-189.

15. Ivanov II, et al. The orphan nuclear receptor ROR $\gamma t$ directs the differentiation program of proinflammatory IL-17 ${ }^{+} \mathrm{T}$ helper cells. Cell. 2006; 126(6):1121-1133.

16. Chen W, et al. Conversion of peripheral $\mathrm{CD} 4{ }^{+} \mathrm{CD} 25^{-}$naive $\mathrm{T}$ cells to $\mathrm{CD} 4{ }^{+} \mathrm{CD} 25^{+}$regulatory T cells by TGF- $\beta$ induction of transcription factor Foxp3. J Exp Med. 2003;198(12):1875-1886.

17. Zhang F, Meng G, Strober W. Interactions among the transcription factors Runx1, ROR $\gamma$ t, and Foxp3 regulate the differentiation of interleukin 17-producing T cells. Nat Immunol. 2008;9(11):1297-1306.

18. Zhou L, et al. TGF- $\beta$-induced Foxp 3 inhibits Th 17 cell differentiation by antagonizing ROR $\gamma t$ function. Nature. 2008;453(7192):236-240.

19. Burgler S, Mantel PY, Bassin C, Ouaked N, Akdis CA, Schmidt-Weber CB. RORC2 is involved in T cell polarization through interaction with the FOXP3 promoter. J Immunol. 2010;184(11):6161-6169.

20. Kanno Y, Vahedi G, Hirahara K, Singleton K, O'Shea JJ. Transcriptional and epigenetic control of $\mathrm{T}$ helper cell specification: molecular mechanisms underlying commitment and plasticity. Annu Rev Immunol. 2012;30:707-731.

21. Jenuwein T, Allis CD. Translating the histone code. Science. 2001;293(5532):1074-1080.

22. Greer EL, Shi Y. Histone methylation: a dynamic mark in health, disease and inheritance. Nat Rev Genet. 2012;13(5):343-357.

23. Roh TY, Cuddapah S, Cui K, Zhao K. The genomic landscape of histone modifications in human T cells. Proc Natl Acad Sci U S A. 2006;103(43):15782-15787.

24. Wei G, et al. Global mapping of H3K4me3 and $\mathrm{H} 3 \mathrm{~K} 27 \mathrm{me} 3$ reveals specificity and plasticity in lineage fate determination of differentiating $\mathrm{CD}^{+} \mathrm{T}$ cells. Immunity. 2009;30(1):155-167.

25. Allan RS, et al. An epigenetic silencing pathway controlling $\mathrm{T}$ helper 2 cell lineage commitment. Nature. 2012;487(7406):249-253.

26. Tachibana M, et al. G9a histone methyltransferase plays a dominant role in euchromatic histone H3 lysine 9 methylation and is essential for early embryogenesis. Genes Dev. 2002;16(14):1779-1791.

27. Shinkai Y, Tachibana M. H3K9 methyltransferase G9a and the related molecule GLP. Genes Dev. 2011; 25(8):781-788.

28. Rice JC, et al. Histone methyltransferases direct different degrees of methylation to define distinct chromatin domains. Mol. Cell. 2003;12(6):1591-1598.

29. Wen B, Wu H, Shinkai Y, Irizarry RA, Feinberg AP. Large histone $\mathrm{H} 3$ lysine 9 dimethylated chromatin blocks distinguish differentiated from embryonic stem cells. Nat Genet. 2009;41(2):246-250.

30. Rougeulle C, et al. Differential histone H3 Lys-9 and Lys-27 methylation profiles on the X chromosome. Mol Cell Biol. 2004;24(12):5475-5484.
31. Ma DK, Chiang CH, Ponnusamy K, Ming GL, Song H. G9a and Jhdm2a regulate embryonic stem cell fusion-induced reprogramming of adult neural stem cells. Stem Cells. 2008;26(8):2131-2141.

32. Mulligan $P$, et al. CDYL bridges REST and histone methyltransferases for gene repression and suppression of cellular transformation. Mol Cell. 2008; 32(5):718-726.

33. Fang TC, et al. Histone H3 lysine 9 di-methylation as an epigenetic signature of the interferon response. J Exp Med. 2012;209(4):661-669.

34. Lehnertz B, et al. Activating and inhibitory functions for the histone lysine methyltransferase G9a in T helper cell differentiation and function. J Exp Med. 2010;207(5):915-922.

35. Powrie F, Leach MW, Mauze S, Caddle LB, Coffman RL. Phenotypically distinct subsets of $\mathrm{CD}^{+} \mathrm{T}$ cells induce or protect from chronic intestinal inflammation in C. B-17 scid mice. Int Immunol. 1993; 5(11):1461-1471.

36. Izcue $A$, et al. Interleukin-23 restrains regulatory $T$ cell activity to drive T cell-dependent colitis. Immunity. 2008;28(4):559-570.

37. O'Connor W, et al. A protective function for interleukin 17A in T cell-mediated intestinal inflammation. Nat Immunol. 2009;10(6):603-609.

38. Powrie F, Leach MW, Mauze S, Menon S, Caddle LB, Coffman RL. Inhibition of Th1 responses prevents inflammatory bowel disease in scid mice reconstituted with CD45RBhi CD4 ${ }^{+} \mathrm{T}$ cells. Immunity. 1994;1(7):553-562.

39. Izcue A, Coombes JL, Powrie F. Regulatory T cells suppress systemic and mucosal immune activation to control intestinal inflammation. Immunol Rev. 2006;212:256-271.

40. Feng T, Qin H, Wang L, Benveniste EN, Elson CO, Cong Y. Th17 cells induce colitis and promote Th1 cell responses through IL-17 induction of innate IL-12 and IL-23 production. J Immunol. 2011; 186(11):6313-6318

41. Leppkes M, et al. ROR $\gamma$-expressing Th17 cells induce murine chronic intestinal inflammation via redundant effects of IL-17A and IL-17F. Gastroenterology. 2009;136(1):257-267.

42. Ito R, et al. Involvement of IL-17A in the pathogenesis of DSS-induced colitis in mice. Biochem Biophys Res Commun. 2008;377(1):12-16.

43. Ogawa A, Andoh A, Araki Y, Bamba T, Fujiyama Y. Neutralization of interleukin-17 aggravates dextran sulfate sodium-induced colitis in mice. Clin Immunol. 2004;110(1):55-62.

44. Roth SY, Denu JM, Allis CD. Histone acetyltransferases. Annu Rev Biochem. 2001;70:81-120.

45. Ludviksson BR, Seegers D, Resnick AS, Strober W. The effect of TGF- $\beta 1$ on immune responses of naive versus memory CD4+ Th1/Th2 T cells. Eur J Immunol. 2000;30(7):2101-2111.

46. Takimoto T, et al. Smad2 and Smad3 are redundantly essential for the TGF- $\beta$-mediated regulation of regulatory $\mathrm{T}$ plasticity and Th 1 development. J Immunol. 2010;185(2):842-855.

47. Chaturvedi CP, et al. Maintenance of gene silencing by the coordinate action of the H3K9 methyltransferase G9a/KMT1C and the H3K4 demethylase Jarid1a/KDM5A. Proc Natl Acad Sci U S A. 2012; 109(46):18845-18850.

48. Bittencourt D, et al. G9a functions as a molecular scaffold for assembly of transcriptional coactivators on a subset of Glucocorticoid Receptor target genes. Proc Natl Acad Sci U S A. 2012;109(48):19673-19678.

49. Lee DY, Northrop JP, Kuo MH, Stallcup MR. Histone H3 lysine 9 methyltransferase G9a is a transcriptional coactivator for nuclear receptors.
J Biol Chem. 2006;281(13):8476-8485.

50 . Vedadi $M$, et al. A chemical probe selectively inhibits G9a and GLP methyltransferase activity in cells. Nat Chem Biol. 2011;7(8):566-574.

51. Kubicek S, et al. Reversal of H3K9me2 by a smallmolecule inhibitor for the G9a histone methyltransferase. Mol Cell. 2007;25(3):473-481.

52. Giresi PG, Kim J, McDaniell RM, Iyer VR, Lieb JD. FAIRE (Formaldehyde-Assisted Isolation of Regulatory Elements) isolates active regulatory elements from human chromatin. Genome Res. 2007;17(6):877-885.

53. Magnani L, et al. Genome-wide reprogramming of the chromatin landscape underlies endocrine therapy resistance in breast cancer. Proc Natl Acad Sci U S A. 2013;110(16):E1490-E1499.

54. Zheng Y, Josefowicz S, Chaudhry A, Peng XP, Forbush K, Rudensky AY. Role of conserved non-coding DNA elements in the Foxp3 gene in regulatory T-cell fate. Nature. 2010;463(7282):808-812.

55 . Kind J, et al. Single-cell dynamics of genome-nuclear lamina interactions. Cell. 2013;153(1):178-192.

56. Montes de Oca R, Andreassen PR, Wilson KL. Barrier-to-Autointegration Factor influences specific histone modifications. Nucleus. 2011;2(6):580-590.

57. Cheng X, Blumenthal RM. Coordinated chromatin control: structural and functional linkage of DNA and histone methylation. Biochemistry. 2010; 49(14):2999-3008.

58. Esteve PO, et al. Direct interaction between DNMT1 and G9a coordinates DNA and histone methylation during replication. Genes Dev. 2006; 20(22):3089-3103.

59. Lee CF, et al. hNaa10p contributes to tumorigenesis by facilitating DNMT1-mediated tumor suppressor gene silencing. J Clin Invest. 2010; 120(8):2920-2930.

60. Bogdanovic O, Veenstra GJ. DNA methylation and methyl-CpG binding proteins: developmental requirements and function. Chromosoma. 2009; 118(5):549-565.

61. Duan Z, Zarebski A, Montoya-Durango D, Grimes HL, Horwitz M. Gfi1 coordinates epigenetic repression of $\mathrm{p} 21 \mathrm{Cip} / \mathrm{WAF} 1$ by recruitment of histone lysine methyltransferase G9a and histone deacetylase 1. Mol Cell Biol. 2005;25(23):10338-10351.

62. Zhu J, et al. Down-regulation of Gfi-1 expression by TGF- $\beta$ is important for differentiation of Th17 and $\mathrm{CD}_{103}{ }^{+}$inducible regulatory T cells. J Exp Med. 2009;206(2):329-341.

63 . Bronevetsky Y, et al. T cell activation induces proteasomal degradation of Argonaute and rapid remodeling of the microRNA repertoire. J Exp Med. 2013; 210(2):417-432.

64. Savage PA, Malchow S, Leventhal DS. Basic principles of tumor-associated regulatory $\mathrm{T}$ cell biology. Trends Immunol. 2013;34(1):33-40.

65. Arrowsmith CH, Bountra C, Fish PV, Lee K, Schapira M. Epigenetic protein families: a new frontier for drug discovery. Nat Rev Drug Discov. 2012; 11(5):384-400.

66. Dong KB, et al. DNA methylation in ES cells requires the lysine methyltransferase G9a but not its catalytic activity. EMBO J. 2008;27(20):2691-2701.

67. Wang X, et al. Transcription of Il17 and Il17f is controlled by conserved noncoding sequence 2 . Immunity. 2012;36(1):23-31.

68. Levings MK, Sangregorio R, Galbiati F, Squadrone $S$, de Waal Malefyt R, Roncarolo MG. IFN- $\alpha$ and IL-10 induce the differentiation of human type $1 \mathrm{~T}$ regulatory cells. JImmunol. 2001;166(9):5530-5539.

69. Eeckhoute J, et al. Cell-type selective chromatin remodeling defines the active subset of FOXA1bound enhancers. Genome Res. 2009;19(3):372-380. 